\title{
HUBUNGAN TINGKAT PENGETAHUAN, SIKAP DENGAN TINDAKAN PENGGUNAAN ALAT PELINDUNG DIRI (APD) PETUGAS KEBERSIHAN DI DINAS LINGKUNGAN HIDUP KABUPATEN GIANYARTAHUN 2020
}

\author{
Ni Komang Ayu Desiani ${ }^{1}$, Ni Ketut Rusminingsih ${ }^{2}$, \\ I Nyoman Purna ${ }^{3}$
}

\begin{abstract}
In maintaining and maintaining the cleanliness of the urban environment especially the cleanliness of the highway, the city government must be supported by optimal resources, including human resources or cleaning workers who are the spearhead in urban cleanliness especially the cleanliness of the highway environment in the 8 research routes. The purpose of this study was to determine the relationship of knowledge levels, attitudes and actions of use personal protective equipment cleaning staff at the Department of the Environment of Gianyar Regency in 2020. The type of research in this study is an observational research method with a cross sectional analysis approach. The number of samples in this study were 82 janitors. The sample in this study used the Cluster Random Sampling technique because researchers randomized from a large population. Test statistics using Chi Square. The results showed that there was a relationship between knowledge and actions of janitors about the use of personal protective equipment $(p=0.019)$, and there was a relationship between attitudes and actions of janitors about the use of personal protective equipment $(p=0.031)$. The conclusion in this study is that there is a significant relationship between knowledge, attitudes with the use of personal protective equipment cleaning officers in the Environmental Service of Gianyar Regency.
\end{abstract}

Keywords:knowledge, attitude, action, PPE

\section{PENDAHULUAN}

Dalam perkembangan dan pertumbuhan suatu kota, kebersihan merupakan salah satu faktor yang menunjang kemajuan suatu kota. Kota yang bersih melambangkan keseriusan pemerintah daerah tersebut dalam menjaga dan memelihara kebersihan kota tersebut. Sampah perkotaan dari hari ke hari semakin meningkat produksinya sejalan dengan pertumbuhan penduduk kabupaten yang meningkat. Untuk mengatasi masalah sampah, dibutuhkan sistem pengelolaan yang baik (1).

Menurut Peraturan Menteri Tenaga Kerja dan Trasmigrasi Republik Indonesia Nomor : PER.08/MEN/VII/2010 tentang Alat Pelindung Diri Pasal 6 ayat 1 
ditetapkan bahwa "Pekerja/buruh dan orang lain yang memasuki tempat kerja wajib memakai atau menggunakan Alat Pelindung Diri sesuai dengan potensi bahaya dan risiko(2).Penggunaan alat pelindung perorangan merupakan salah satu cara alternative untuk melindungi pekerja dari bahaya-bahaya kesehatan. Namun perlu diperhatikan bahwa alat pelindung diri perorangan harus sesuai dan adekuat untuk bahaya-bahaya tertentu, resisten terhadap kontaminan udara, dibersihkan dan dipelihara dengan baik, serta sesuai untuk pekerja yang memakainya (3).

Berdasarkan pengamatan awal peneliti, pada petugas kebersihan sampah Dinas Lingkungan Hidup Kabupaten Gianyar, pemindahan sampah dari Tempat Pembuangan Sampah Sementara (TPSS) ke truk menggunakan aktivitas tangan dan secara langsung tanpa menggunakan APD hanya beberapa orang yang memakai APD. Berdasarkan uraian latar belakang tersebut, penulis tertarik untuk melakukan penelitian dengan judul "Hubungan Tingkat
Pengetahuan, Sikap Dengan Tindakan Penggunaan Alat Pelindung Diri (APD) Petugas Kebersihan Di Dinas Lingkungan Hidup Kabupaten Gianyar Tahun 2020".

Adapun tujuan dari penelitian ini adalah (1) Untuk mengetahui pengetahuan petugas kebersihan dengan penggunaan APD di Dinas Lingkungan Hidup Kabupaten Gianyar Tahun 2020, (2) Untuk mengetahui sikap petugas kebersihan dengan penggunaan APD di Dinas Lingkungan Hidup Kabupaten Gianyar Tahun 2020, (3) Untuk mengetahui tindakan petugas kebersihan dengan penggunaan APD di Dinas Lingkungan Hidup Kabupaten Gianyar Tahun 2020, dan (4) Untuk menganalisis hubungan tingkat pengetahuan, sikap dengan tindakan penggunaan alat pelindung diri (APD) petugas kebersihan Di Dinas Lingkungan Hidup Kabupaten Gianyar tahun 2020. Adapun manfaat dari penelitian ini adalah memberikan informasi dan evaluasi kepada pihak manajemen agar memberikan informasi mengenai personal hygiene 
pada petugas kebersihan serta memberikan APD yang cukup memadai guna memberikan perlindungan bagi petugas kebersihan terhadap penyakit yang diakibatkan oleh sampah dan memberikan informasi.

\section{Metode}

Jenis penelitian dalam penelitian ini adalah metode penelitian observasional dengan pendekatan analisis Cross Sectional dimana variabel sebab atau risiko dan akibat atau kasus yang terjadi pada objek penelitian di ukur atau dikumpulkan dalam waktu bersamaan (4).Variabel terikat dalam penelitian ini yaitu tindakan penggunaan APD pada petugas kebersihan variabel bebas dalam penelitian ini yaitu pengetahuan, sikap penggunaan APD pada petugas kebersihan, dan variabel penggangunya adalah umur, pendidikan, dan lama bekerja.Penelitian ini dilakukan di Dinas Lingkungan Hidup Kabupaten Gianyar.Penelitian ini dilaksanakan dari bulan April sampai dengan Juni 2020.Populasi dalam penelitian ini adalah seluruh petugas kebersihan di Dinas Lingkungan Hidup Kabupaten Gianyar dengan jumlah petugas kebersihan pada Dinas Lingkungan Hidup Kabupaten Gianyar sebanyak 453 orang yang tersebar di 19 rute penyapuan/pengangkutan sampah. Jumlah sampel ditentukan dengan menggunakan rumus penentuan besar sampel (4) adalah sebagai berikut :

$$
n=\frac{N}{1+N\left(d^{2}\right)}
$$

Keterangan :

$\mathrm{N}=$ besar populasi

$\mathrm{n}$ = besar sampel

$\mathrm{d}=$ tingkat kepercayaan/ketetapan yang diinginkan $(0,1)$

Diperoleh besar sampel sebanyak 82 orang.

Teknik atau pengambilan sampel yang digunakan dalam penelitian ini adalah Cluster Random Sampling yaitu pengambilan sampel secara berkelompok, bukan terhadap subjek secara individual(5).Pengumpulan data primer dilakukan dengan wawancara langsung kepada responden, yaitu dengan lembar observasi dan kuesioner tentang pengetahuan, sikap 
dan tindakan penggunaan APD pada petugas kebersihan.Sedangkan data sekunder diperoleh dengan mengumpulkan data dari data yang sudah ada, yaitu berupa data dari Dinas Lingkungan Hidup Kabupaten Gianyar yaitu data jumlah petugas kebersihan, dan profil Dinas Lingkungan Hidup Kabupaten Gianyar.Pengolahan data menggunakan kuesioner danobservasi dibuat sesuai dengan pertanyaan dimana jawaban dikodekan dengan "centang" pada kolom.Untuk mendapatkan persentase maka data dianalisis menggunakan rumus (6)yaitu :

$$
=\frac{\text { jumlahnilai yang di peroleh }}{\text { jumlahpertanyaan }} \times 100 \%
$$

Dengan kategori untuk masingmasing variabel adalah $0-30 \%=$ kurang, $40-60 \%=$ sedang, $70-100 \%$ =baik. Dari data yang sudah terkumpul dimasukkan ke dalam uji statistik menggunakan uji Chi Square.Dalam menentukan hubungannya dilakukan pengujian terhadap $\mathrm{H}_{\mathrm{o}}$ dengan derajat kepercayaan $0,05 \quad(5 \%) . \quad \mathrm{H}_{\mathrm{o}}$ ditolak apabila signifikan $<0,05$ berarti ada hubungan pengetahuan, sikap, dengan tindakan tentang penggunaan APD pada petugas kebersihan. Bila $\mathrm{H}_{\mathrm{o}}$ diterima berarti tidak ada hubungan pengetahuan, sikap, dengan tindakan tentang penggunaan APD pada petugas kebersihan.

\section{HASIL DAN PEMBAHASAN}

\section{Karakteristik responden}

Dari 82 responden yang diteliti, diperoleh hasil mayoritas berumur 3645 tahun yaitu sebanyak 40 orang (48.8\%), masa kerja responden mayoritas yang bekerja >10 tahun sebanyak 50 orang $(61.0 \%)$, pendidikan responden paling banyak yaitu tamat SMA sebanyak 49 orang (59.8\%).

\section{Distribusi variabel penelitian}

a. Pengetahuan responden

Berdasarkan hasil yang telah didapatkan bahwa tingkat pengetahuan responden tentang penggunaan APD, dimana dari 82 orang responden mayoritas memiliki tingkat pengetahuan baik sebanyak 61 orang (74.4\%).hal ini menunjukkan bahwa sebagaian besar responden sudah 
memiliki pengetahuan yang baik tentang penggunaan APD, jenis-jenis APD, manfaat APD saat bekerja yang sesuai dengan pekerjaan mereka.

b. Sikap responden

Berdasarkan hasil yang telah didapatkan bahwa tingkat sikap responden tentang penggunaan APD, dimana dari 82 orang responden mayoritas memiliki tingkat sikap baik sebanyak 54 orang (65.9\%).Responden sudah memiliki sikap baik tentang penggunaan APD, dalam cuaca yang sangat panas tetap harus menggunakan APD secara baik dan benar, serta setuju dengan pemakaian APDyang dapat mencegah terjadinya kecelakaan kerja.

c. Tindakan responden

Berdasarkan hasil yang telah didapatkan bahwa tingkat tindakan responden tentang penggunaan APD, dimana dari 82 orang responden mayoritas memiliki tingkat tindakan baik sebanyak 43 orang (52.4\%).Sebagian besar responden sudah memiliki tindakan yang baik seperti memakai APD yang lengkap saat bekerja.

\section{Analisis hubungan antar variabel}

a. Pengetahuan dengan tindakan responden dalam penggunaan APD

Tabel 4

Hubungan pengetahuan dengan tindakan responden dalam penggunaan APD

\begin{tabular}{|c|c|c|c|c|c|c|c|c|c|}
\hline \multirow[t]{3}{*}{ Pengetahuan } & \multicolumn{6}{|c|}{ Tindakan } & \multirow{2}{*}{\multicolumn{2}{|c|}{ Total }} & \multirow[t]{3}{*}{ Nilai P } \\
\hline & \multicolumn{2}{|c|}{ Kurang } & \multicolumn{2}{|c|}{ Sedang } & \multicolumn{2}{|c|}{ Baik } & & & \\
\hline & $\mathrm{n}$ & $\%$ & $\mathrm{n}$ & $\%$ & $n$ & $\%$ & $\mathrm{n}$ & $\%$ & \\
\hline Kurang & 0 & 0.0 & 2 & 20.0 & 8 & 80.0 & 10 & 100 & 0.019 \\
\hline Sedang & 4 & 36.4 & 5 & 45.5 & 2 & 18.2 & 11 & 100 & \\
\hline Baik & 5 & 8.2 & 23 & 37.7 & 33 & 54.1 & 61 & 100 & \\
\hline Total & 9 & 11.0 & 30 & 36.6 & 43 & 524 & 82 & 100 & \\
\hline
\end{tabular}

Hasil analisis hubungan pengetahuan dengan tindakan petugas kebersihan berdasarkan uji statistik dengan menggunakan uji Chi-Square didapatkan hasil $p$-value $=0.019$, hasil menunjukan bahwa nilai $\mathrm{p}<\mathrm{a}(0.05)$ yang berarti $\mathrm{H}_{\mathrm{o}}$ ditolak atau ada hubungan yang bermakna/signifikan antara pengetahuan dengan tindakan responden. Hasil penelitian ini sejalan dengan teori yang menyatakan bahwa pengetahuan merupakan hasil tahu dan 
ini terjadi setelah orang melakukan penginderaan terhadap suatu obyek tertentu.Pengetahuan merupakan domain yang sangat penting dalam membentuk tindakan seseorang (overt behavior) (7).Terbentuknya perilaku dapat terjadi karena proses kematangan dan dari proses interaksi dengan lingkungan. Cara inilah yang paling besar pengaruhnya terhadap perilaku manusia. Terbentuknya dan perubahan perilaku karena proses interaksi antara individu dengan lingkungan melalui suatu proses yakni b. Hubungan sikap dengan tindakan responden

Tabel 8

Hubungan sikap dengan tindakan responden dalam penggunaan APD

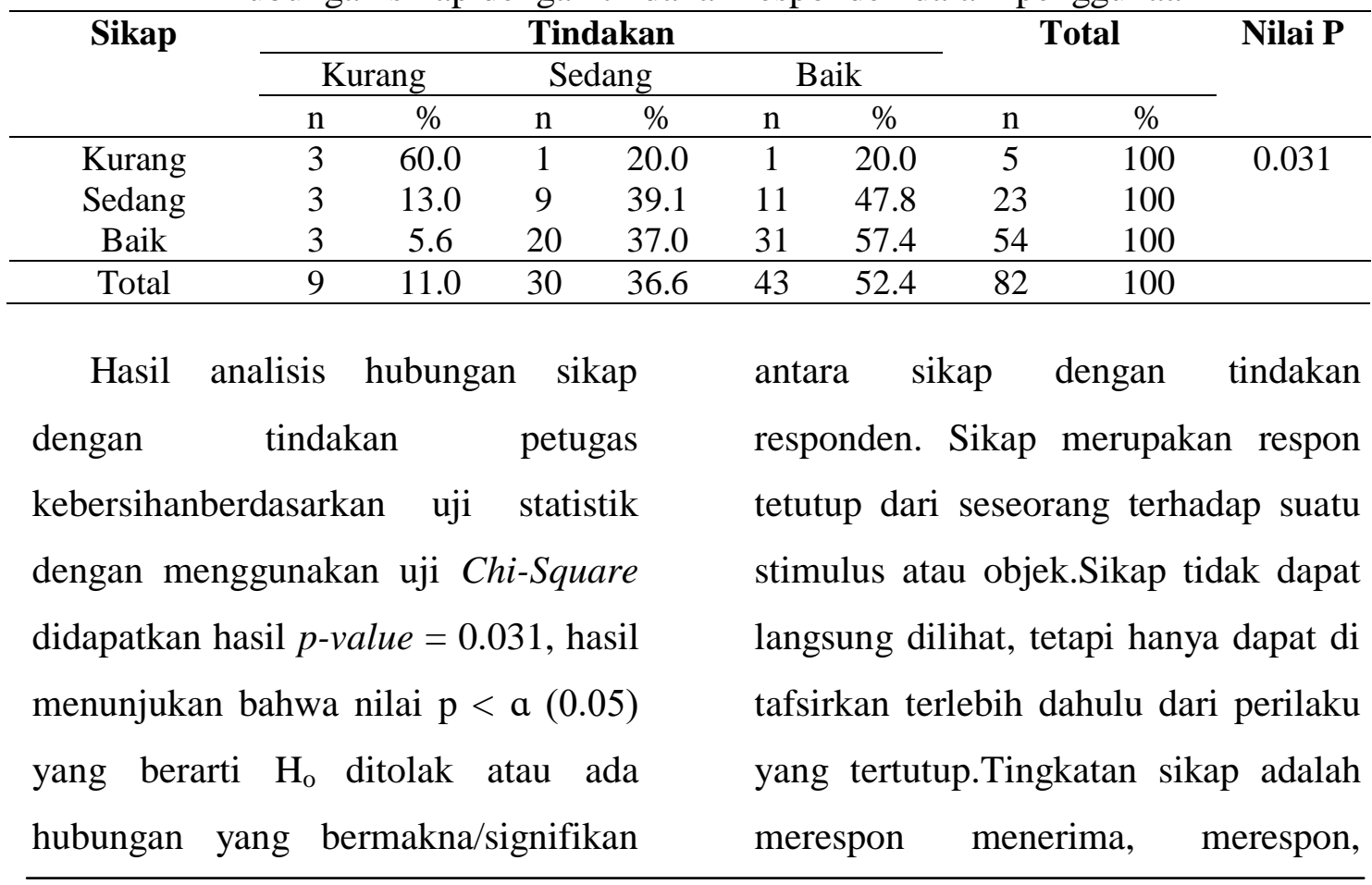


menghargai,dan bertanggung jawab (8).Faktor sarana dan prasarana merupakan penentu dalam terlaksananya tindakan yang sesuai dengan aturan yang telah ditetapkan oleh sebuah perusahaan atau sebuah instansi (10).

\section{KESIMPULAN DAN SARAN}

Berdasarkan hasil penelitian yang telah dilakukan pada 82 responden tentang Hubungan Tingkat Pengetahuan, Sikap Dengan Tindakan Penggunaan Alat Pelindung Diri (APD)Petugas Kebersihan di Dinas Lingkungan Hidup Kabupaten Gianyar Tahun 2020 dapat ditarik kesimpulan sebagai berikut :

1. Responden memiliki pengetahuan baik tentang penggunaan APD yaitu sebanyak 61 orang $(74.4 \%)$.

2. Responden memiliki sikap yang baik tentang penggunaan APD yaitu sebanyak 54orang (65.9\%).

3. Responden memiliki tindakan yang baik tentang penggunaan APD sebanyak 43orang (52.4\%).

4. Ada hubungan yang signifikan/bermakna antara pengetahuan, sikap dengan tindakan petugas kebersihan tentang penggunaan alat pelindung diri (APD) di Dinas Lingkungan Hidup Kabupaten Gianyar Tahun 2020.

Berdasarkan kesimpulan diatas dapat disarankan sebagai berikut:

1. Bagi Dinas Lingkungan Hidup Kabupaten Gianyar diharapkandapat meningkatkan pengetahuan petugas kebersihan dengan memberikan penyuluhan tentang pentingnya penggunaan APD saat bekerja, dan dapatmemberikan APD secara rutin setiap tahunnya sehingga dapat meminimalisirkan kecelakaan kerja pada petugas kebersihan.

2. Bagi petugas kebersihan di Dinas Lingkungan Hidup Kabupaten Gianyar diharapkan dapat menjaga kesehatan dan keselamatan kerja dengan cara menggunakan alat pelindung diri selama melakukan pekerjaan. 


\section{DAFTAR PUSTAKA}

1. MANAJEMEN KERJA

PENYAPU JALAN DI KOTA

PEKANBARU Ellin Noviani

Email : 2016;3(2).

2. Kemennakertrans. Peraturan

Menteri Tenaga Kerja dan

Transmigrasi Republik

Indonesia. Peratur Menteri.

2010;1-69.

3. Sumantri. Kesehatan

Lingkungan. Jakarta: Kencana; 2015.

4. Soekidjo Notoatmodjo. Metode Penelitian Kesehatan. Jakarta:

PT. Rineka Cipta; 2010.

5. Saifuddin Azwar. Metode Penelitian. Yogyakarta: Pustaka Pelajar; 2010.

6. Soekidjo Notoatmodjo. Metode Penelitian Kesehatan. Jakarta:

PT. Rineka Cipta; 2002.

7. Soekidjo Notoatmodjo. Metode
Penelitian Kesehatan. Jakarta:

PT. Rineka Cipta; 2012.

8. Soekidjo Notoatmodjo.

Pendidikan Dan Perilaku

Kesehatan. Jakarta: PT. Rineka

Cipta; 2003.

9. Afni. Hubungan Antara

Pengetahuan Dan Sikap Dengan Tindakan Penggunaan Alat Pelindung Diri Pada Tenaga Kerja Di PT Tropica Cocoprima

Desa Lelema Kecamatan Tumpaan Kabupaten Minahasa Selatan.

10. Azrul Azwar. Pengantar Ilmu Kesehatan Lingkungan. Jakarta: Mutiara Sumber Penabur Benih; 2006. 